\title{
DESENVOLVENdO PESSOAS: ESTRATÉgIAS DIDÁTICAS FACILITADORAS PARA O AUTOCONHECIMENTO NA FORMAÇÃO DO ENFERMEIRO'
}

\author{
Elizabeth Esperidião ${ }^{2}$ \\ Denize Bouttelet Munari ${ }^{3}$ \\ Jeanne Marie R. Stacciarini ${ }^{4}$
}

Esperidião E, Munari DB, Stacciarini JMR. Desenvolvendo pessoas: estratégias didáticas facilitadoras para o autoconhecimento na formação do enfermeiro. Rev. Latino-am Enfermagem 2002 julho-agosto; 10(4):516-22.

Estudo elaborado partindo-se da disciplina Saúde Mental-l sobre o desenvolvimento do enfermeiro por meio do estímulo ao autoconhecimento. Foram objetivos refletir sobre o autoconhecimento como ferramenta na formação do enfermeiro e analisar estratégias didáticas facilitadoras ao desenvolvimento dessa habilidade. Os dados foram coletados no decorrer da disciplina, utilizando-se registros escritos, auto-avaliação e avaliação da disciplina. Os resultados mostraram que o aluno tem oportunidade de desenvolver seu autoconhecimento sendo que determinadas técnicas de ensino estimulam o contato com aspectos pessoais, facilitando a descoberta de potencialidades para a prática profissional. Concluímos que a disciplina tem desempenhado papel fundamental na formação do enfermeiro.

DESCRITORES: ensino, enfermagem, saúde mental

\section{deVeloping people didactic Strategies to PROMOte Self-KNOWLEDGe IN THE NURSE EDUCATION}

This is a study elaborated on the basis of the course Mental Health-I, about the nurse formation through self-knowledge motivation. The goals were, to reflect about self-knowledge as a tool in the nurse formation and to analyze didactic strategies to facilitate its development. The data was collected during the course using written registers, self-evaluation and course evaluation. Results showed that the student has the opportunity to develop her/his self-knowledge given that some teaching techniques stimulate the contact with personal issues, facilitating the discovery of potentiality for the professional practice. We concluded that the course has been playing a fundamental role in the nurse education.

DESCRIPTORS: teaching, nursing, mental health

\section{DESARROLLANDO PERSONAS: ESTRATEGIAS DIDACTICAS PARA FACILITAR EL AUTOCONOCIMIENTO EN LA FORMACION DEL ENFERMERO}

Estudio elaborado a partir del curso de Salud Mental sobre el desarrollo del enfermero a través de estímulos para el autoconocimiento. Los objetivos fueron, reflexionar sobre el autoconocimiento como herramienta en la formación del enfermero y analizar estrategias didácticas que faciliten el desarrollo de esta habilidad. Los datos fueron recolectados con forme al desarrollo del curso, utilizando registros escritos, autoevaluación y evaluación del curso. Los resultados mostraron que el alumno tiene la oportunidad de desarrollar su autoconocimiento dado que determinadas técnicas de enseñanza estimulan el contacto con aspectos personales, facilitando el descrubrimiento de potencialidades personales para la práctica profesional. Concluimos que el curso ha desempeñado un papel fundamental en la formación del enfermero.

DESCRIPTORES: enseñanza, enfermería, salud mental

\footnotetext{
${ }^{1}$ Projeto financiado pelo CNPq e desenvolvido pelo NEPSI/FEN/UFG; ${ }^{2}$ Doutoranda da Escola de Enfermagem de Ribeirão Preto, da Universidade de São Paulo, Centro Colaborador da OMS para o desenvolvimento da pesquisa em enfermagem, Professor Assistente; ${ }^{3}$ Professor Titular, email: denize@fen.ufg.br. Faculdade de Enfermagem da Universidade Federal de Goiás; ${ }^{4}$ Professor Doutor, School of Nursing - Umass/Amherst/ USA
} 


\section{INTRODUÇÃO}

O fato de exercermos a docência, preparando enfermeiros há mais de uma década, tem nos levado a questionar alguns aspectos da formação desse profissional, entendida por nós além dos aspectos estritamente acadêmicos, a qual considera não só a preparação do enfermeiro do ponto de vista técnicocientífico de alto nível, mas também a formação do ser humano que habita o profissional.

A visão holística e existencialista de homem auxilia na compreensão de algumas inquietações que têm nos acompanhado ao longo desses anos. Elas se sustentam por percebermos que pouca atenção tem sido dada ao cuidado do homem como um todo, tanto no que se refere à assistência à saúde, como à formação de recursos humanos ligados à área. Ao contrário, apesar do amplo discurso da integralidade do ser humano, como ser biopsicossocioespiritual, ele é visto sob fragmentos, deixando-se de compreendê-lo na sua amplitude e, ainda, esquecendo-se da premissa básica de que, como um todo, é diferente da soma de suas partes.

Sabemos que, apesar de existir a semente de uma proposta transformadora, no ensino de enfermagem, a qual contempla aspectos de natureza filosófica e pedagógica incorporados no currículo, ainda se privilegia a competência técnica do profissional, desconsiderandose a necessidade de instrumentalizar o processo de crescimento interno de cada um ${ }^{(1-3)}$.

Dessa maneira, as tendências atuais voltadas para a formação do profissional enfermeiro, com uma postura crítica e reflexiva, com habilidades que vão além dos aspectos técnicos, constituem um grande desafio para as instituições formadoras.

Neste trabalho, vislumbramos a possibilidade de nos aproximarmos dessa questão, com vistas ao aprofundamento de formas e estratégias para a formação do enfermeiro, de modo pleno e consciente, de forma que privilegie seu desenvolvimento técnico e pessoal, na mesma intensidade e ordem de importância no processo educativo.

\section{REVISÃO DA LITERATURA}

Nossa experiência possibilita verificar que o processo de formação do enfermeiro não tem englobado questões que permitam fortalecer seu equipamento emocional, a despeito das inúmeras situações ansiogênicas às quais é submetido durante o curso.

O ensino das profissões de saúde deverá passar por profundas mudanças nas próximas décadas, uma vez que se evidenciam sinais de esgotamento, exigindo a construção de novos modelos de formação e capacitação de recursos humanos em saúde ${ }^{(4)}$.

Às vésperas do terceiro milênio, vemos eclodir um movimento de globalização que nos impõe a necessidade de repensar as relações do homem no mundo ${ }^{(5)}$. Mais que isso, percebemos a necessidade de os profissionais da área da saúde repensarem sua compreensão de mundo, de homem, do modo de assistir o ser humano, de lidar com a saúde e com a doença.

Tais questões devem ser discutidas e experienciadas no decorrer do período em que o aluno passa pela academia, pois, na medida em que ele for compreendido na sua totalidade, enquanto ser humano, estará capacitando-se e tornando-se mais comprometido com o atendimento dispensado às pessoas.

Assim, ao reconhecermos o futuro profissional como pessoa, possibilitamos a ele oportunidade para reconhecer a si mesmo, como instrumento básico no cuidado, no sentido de facilitar o estabelecimento de relações mais humanizadas consigo mesmo e com os outros. "A eficiência do enfermeiro depende diretamente de suas atitudes para consigo mesmo e para com os outros. A vida e as pessoas é que nos dão materiais experiências para que adquiramos os conhecimentos que nos levarão a atitudes"(6).

Precisamos, portanto, assumir efetivamente uma posição diante dos desafios postos ao ser humano para o enfrentamento de uma nova era, cujas tendências exigem, do profissional do futuro, o perfil de uma pessoa capaz de investir no seu auto conhecimento, que seja ágil e criativo na resolução de problemas, que tenha conhecimento variado e eclético e com habilidades nas relações humanas.

O movimento básico para este fim é a educação do homem para uma nova ordem, aspecto aprofundado por vários pesquisadores ${ }^{(7-10)}$. Tal movimento é orientado para a busca da excelência do ser humano como pessoa, considerando a educação como um processo de integração do corpo, dos sentimentos, da mente e do espírito, de forma completa e equilibrada, que oferece ao mundo pessoas informadas a seu respeito e também dirigidas a ela ${ }^{(11)}$. 
A busca no processo de formação do enfermeiro para o autoconhecimento é fundamental, pois, como ser humano, "experimenta várias crises, ou possibilidades de crise e leva tudo isso, queira ou não, para o encontro com o seu cliente. Estão incluídos aqui, todos os problemas existenciais, conflitos não resolvidos e muitas outras dificuldades vivenciais que, obviamente, o curso não deu subsídios para superação"(6).

Assim, vale a pena uma reflexão sobre o papel das instituições formadoras, a respeito de como instrumentalizar o profissional com requisitos mínimos para o desenvolvimento da competência interpessoal, compreendendo que ela só é desenvolvida se o sujeito do processo ensino-aprendizagem estiver disposto, pelo menos, a considerar o autoconhecimento como peça fundamental na sua formação profissional ${ }^{(12-14)}$.

Consideramos que o grande desafio, quando falamos em desenvolver atitudes mais humanizadoras na assistência, é garantir esse aspecto como fundamental na formação de profissionais de saúde, dentro ou fora da academia. Assim, acreditamos que essa abordagem deve fazer parte de um projeto pedagógico das instituições formadoras, no sentido de não se tornar uma ação isolada e sem significância.

A humanização do processo ensinoaprendizagem deve ser vista como um dos imperativos do nosso tempo, pois o que se observa é a ênfase da dimensão intelectual ou cognitiva, em detrimento quase que total das dimensões emocional e social que integram a totalidade da pessoa humana. O objetivo último desse processo educacional é o desenvolvimento global, harmônico, holístico, da pessoa como unidade cognitiva e emocional ${ }^{(15-16)}$.

Ao valorizar a humanização das relações interpessoais, estamos facilitando o crescimento intelectual e emocional do ser humano, pois, para isso, acionamos habilidades para o estabelecimento de relações construtivas, no sentido de obtermos a compreensão e a aquiescência de quem precise de ajuda ${ }^{(6)}$. Em situações onde se possibilita ao aluno perceber-se enquanto pessoa e mostrar-se não somente como profissional, sua participação no processo é intensificada e valorizada, sendo que essas experiências são reconhecidas como contribuições significativas para sua formação ${ }^{(3,6)}$.

Essa visão é considerada antipositivista e a mais humana das atividades dos profissionais de saúde, que pode contribuir para um contato efetivo, mais empático e, conseqüentemente, mais ético, entre eles e a população assistida ${ }^{(17)}$.

No entanto, sabemos das dificuldades a serem transpostas quando falamos em trabalhar questões pessoais na formação de profissionais. Vários estudos ${ }^{(18-}$ 20) apontam elementos concretos dessas dificuldades, mostrando que esse movimento é carregado de resistências internas, medo de lidar com as emoções e sentimentos e, geralmente, é deixado de lado, em função do atendimento dos aspectos técnicos a serem considerados, prioritariamente, no atendimento em saúde.

Acreditamos que a área da Saúde Mental pode contribuir nesse processo, uma vez que, por natureza, trabalha com as emoções e sentimentos, considera o ser humano na totalidade e pode ajudar na formação de profissionais mais comprometidos com a humanização da assistência à saúde. A literatura ${ }^{(2,15-16,21-25)}$ demonstra a importância de investir na formação básica dos profissionais da saúde, para que estes sejam críticos com relação a sua atuação profissional.

Partindo do conteúdo exposto e de nossa experiência, sempre ligada à área de Saúde Mental, desenvolvemos este estudo com o objetivo de refletir sobre o autoconhecimento como ferramenta na formação do enfermeiro e analisar as estratégias didáticas e o conteúdo programático como facilitadores ao desenvolvimento dessa habilidade.

\section{METODOLOGIA}

Pesquisa exploratória descritiva, realizada no decorrer da disciplina Saúde Mental I, ao longo de três anos em que ela passou a ser oferecida, após mudança curricular do Curso de Graduação em Enfermagem da Faculdade de Enfermagem da Universidade Federal de Goiás.

As estratégias adotadas para trabalhar o conteúdo da referida disciplina diferem das convencionais, tendo como premissa básica o envolvimento do aluno no processo ensinoaprendizagem, de modo a comprometê-lo como sujeito ativo da elaboração do conhecimento teórico, partindo de vivências individuais e coletivas. Tais estratégias consistem de construção de peças teatrais e inventos, 
dramatizações, painéis, aulas dialogadas, observação em campo, entrevistas gravadas, sempre com a finalidade de contribuir para o desenvolvimento dos vários conceitos discutidos no conteúdo programático da disciplina.

Sujeitos do estudo: alunos da $2^{\mathrm{a}}$ série do curso de Graduação em Enfermagem (50 alunos por turma)

Período: durante os anos de 1997, 1998 e 1999.

Instrumentos e Coleta dos Dados: foram utilizadas três fontes distintas: a) registros em diários de campo realizados pelas docentes, no decorrer das turmas da disciplina Saúde Mental I (1997 a 1999); b) ficha de avaliação da disciplina, preenchida por todos os alunos, contendo questões relativas ao tema em estudo; c) questionário com questões abertas e fechadas, respondido por um total de 62 alunos, sendo 22 da $2^{\mathrm{a}}$ série (G1), 15 , da $3^{\mathrm{a}}$ série (G2), e 25 , da $4^{\mathrm{a}}$ série (G3); cabe ressaltar que os mesmos pertenciam, respectivamente, à turmas dos anos citados. O propósito da pesquisa foi apresentado a toda turma e aqueles que se dispuseram em participar deram o consentimento por escrito, em formulário próprio para a utilização dos dados, seguindo as normas de pesquisa com seres humanos, do Conselho Nacional de Saúde, atendendo à resolução 196/96. O projeto foi aprovado pelo Comitê de Ética da Universidade Federal de Goiás.

\section{ANÁLISE E DISCUSSÃO DOS DADOS}

As descrições dos sujeitos foram submetidas à análise de conteúdo ${ }^{(26)}$, constituindo categorias a partir da temática central.

Para a caracterização do material, utilizamos a técnica de análise temática, entendendo que, assim, melhor contemplaríamos e representaríamos as respostas obtidas, por meio do recorte do conjunto de dados, a freqüência da apresentação de determinados temas no discurso dos sujeitos, considerados de maior relevância para o estudo ${ }^{(26)}$. Além da análise de conteúdo, recorremos à estatística descritiva, apresentando dados de freqüência.

O conteúdo analisado nos instrumentos de coleta de dados permitiu sua classificação em três grandes categorias: autoconhecimento, conhecimento do outro e experienciando a disciplina. Essa categorização ocorreu de forma similar nas três turmas pesquisadas.
Autoconhecimento - os conteúdos abaixo sugerem que a disciplina contribui para o despertar de si mesmo e para melhor visualização de mundo, levando ao crescimento pessoal: ...passamos a ver o mundo de forma diferente; aprendi a me conhecer, conhecendo o outro; a disciplina nos mostrou que devemos nos conhecer melhor para estar apto a cuidar de outras pessoas... aprendi a me ver como um profissional e também a crescer como pessoa; ...saúde mental é, antes de tudo, saber conhecer-se.

Os conteúdos que remetem à disciplina, como auxiliar na compreensão de si mesmo, do outro, valorizando o relacionamento interpessoal enquanto pessoa e profissional, de forma harmoniosa, integrada e completa, deixam evidentes que o aprendizado torna-se mais sólido e mais bem assimilado quando vem ao encontro de necessidades pessoais de auto-realização. Pesquisa realizada sobre o tema atesta que a aprendizagem torna-se mais significativa quando envolve o desenvolvimento global do ser humano, numa visão holística com fundamentação humanística ${ }^{(15)}$.

Conhecimento do outro - as expressões dos sujeitos, valorizam a inter-relação e a compreensão do ser humano a partir da visão holística de homem: na relação com o paciente, no modo de ver a pessoa e o indivíduo como um todo; ...a disciplina ajudou a entender o ser humano como pessoa e não como doença; ...em todas as ocasiões estamos lidando com a saúde mental das pessoas, o que influencia na saúde do corpo como um todo; hoje já consigo me controlar para tomar uma atitude...isso melhora a minha interação com outras pessoas.

Experienciando a disciplina - As falas dos sujeitos referem-se à postura do professor, à pertinência encontrada entre objetivos e conteúdos, indicando, ainda, a aplicabilidade para o curso e para a profissão: não é apenas a disciplina que contribui...é adquirido em um processo em cadeia: disciplina - professor - aluno - interesse pessoal; conteúdos abordados foram pertinentes aos objetivos da disciplina; as aulas, o modo de dá-las, o conteúdo me ajudaram bastante....

Tais afirmações reforçam a idéia de que ensinar é facilitar a aprendizagem, criando condições para que o outro, a partir dele mesmo, aprenda e cresça ${ }^{(27)}$. Assim, coloca-se a ênfase nas relações interpessoais e no crescimento pessoal que delas resultam. Como conseqüência, há um redimensionamento em valores, conceitos e papéis sociais que se manifestam também na esfera da educação, modificando a característica das relações docente/discente, que inegavelmente alteram, a qualidade do processo ensino-aprendizagem ${ }^{(28)}$. 
Nossas observações evidenciam, também, maior proximidade na relação professor/aluno, assim como apontam o fortalecimento das relações interpessoais no grupo de alunos. Tais afirmações foram, por vezes, expressas por alguns alunos, durante as aulas ou em situações onde nos procuravam em particular, ora para elogiar, até mesmo agradecer, ou não raro, para pedir ajuda ou aconselhamento diante de dificuldades pessoais, na família ou com colegas de faculdade.

No decorrer deste estudo, foi possível perceber o processo de envolvimento e compromisso dos alunos com a disciplina ao longo do processo. A relação docentediscente também foi muito enfatizada no processo de descobrir o "outro" como elemento fundamental ao crescimento pessoal. Se, no início dos encontros, havia, para eles, uma certa ambigüidade entre a maneira descontraída de aprender e o alto nível de exigência dos professores, que implicava um pensamento de incompreensão ou de lógica contrastante (manifesto por eles), ao final, houve uma retomada de postura por parte dos alunos, sempre acompanhada de uma leitura compreensiva do processo de aprender com o outro, de observar os limites e responsabilidades na relação humana.

Verificamos que os dados quantitativos corroboram os aspectos evidenciados na categoria "Experienciando a Disciplina"; quando investigamos se o objetivo da disciplina foi cumprido, para a amostra total de sujeitos (62 indivíduos), obtivemos que 61 alunos $(98,4 \%)$ respondem afirmativamente e apenas um "missing" (1,6\%).

No que se refere às estratégias de ensino, o resultado geral, para os alunos de todas as séries, revela que a dramatização (83,9\%), a discussão em sala $(85,2 \%)$ e a discussão em grupos (82,3\%) são relacionadas como aquelas que mais propiciam o aprendizado do autoconhecimento. Evidenciamos também, dentre as estratégias didáticas oferecidas, que a entrevista gravada apresenta maior percentual negativo, ou seja, não foi mencionada como facilitadora do processo.

Das unidades temáticas contidas no programa, buscamos classificar, em ordem de importância, os assuntos contemplados pela disciplina. No geral, a distribuição das freqüências obtidas para a classificação dos tópicos que compõem o conteúdo programático, em ordem de importância, que favorece o autoconhecimento dos sujeitos, não permite sugerir aqueles que foram considerados como mais ou como menos importantes. Porém, houve maior percentual, para "o homem e suas relações" (61,3\%) e "criatividade, autopercepção, autoconhecimento" (79\%), quando consideramos o somatório das três primeiras classificações dos sujeitos. De forma oposta, o conteúdo denominado "a morte" $(61,3 \%)$ recebe as quatro últimas classificações.

Chama a atenção que, em algumas respostas, há indícios de certa incompreensão quanto ao tipo e objetivo das estratégias de ensino utilizadas, especialmente aquelas que, pela própria natureza, tinham cunho mais lúdico, e, nem por isso, deixam de conter relevante valor pedagógico. Enquanto a maioria das respostas enaltecia a metodologia implementada, houve aquelas que denotaram a falta de compreensão dos objetivos de determinadas estratégias usadas nas aulas, aparentemente sem pertinência com o processo de formação. Citações como: ...seria interessante deixar claro que toda e qualquer atividade tem caráter didático; as oficinas, fazer brincadeiras, não deviam ser atividades obrigatórias... não é um tipo de aula 'aproveitável'...; mostram que ainda há dificuldade de o aluno entender e assimilar propostas diferenciadas de ensino não usual.

No entanto, encontramos dados que ratificam tais resultados discutidos em outra pesquisa,onde se trabalhou a valorização de técnicas de ensino não tradicionais, como elementos facilitadores do processo ensino-aprendizagem, que sinalizavam o fato de ela favorecerem o enriquecimento individual decorrente desse tipo de abordagem ${ }^{(3)}$. As citações a seguir ilustram essa afirmação: a disciplina mostrou uma maneira gostosa de entender a saúde mental; as estratégias de ensino utilizadas foram extremamente satisfatórias; houve momentos de descontração e de retribuir o que estava sendo passado.

De igual forma, os recursos utilizados foram destacados na avaliação feita pelos alunos, pela informalidade nas discussões de que tiveram a oportunidade de participar, pois a experiência que trazem, geralmente vem acompanhada de estratégias que valorizam o repasse passivo de teorias formais, de convenções nem sempre condizentes com o pensamento do estudante. Nesse sentido, há, também, correspondência entre nossos resultados encontrados e o estudo citado acima, cujas respostas apontam que a maneira descontraída de ensinar pode vir acompanhada de reflexões teórico-práticas pertinentes. Enfatiza-se, 
assim, o como ensinar, na medida em que podemos despertar ou elevar o grau de interesse e participação do aluno em relação ao que se propõe.

A metodologia de transmissão de conhecimentos muito usada, onde o aluno, ao ser considerado página em branco, recebe "de fora novos conhecimentos"*, pode gerar alunos acríticos, poucos criativos, passivos dependentes e conformados ${ }^{(1,29)}$. Ainda hoje, sentimos os reflexos desse modelo, apesar de tentativas inovadoras no processo de formação. Falas como: ...sugiro aulas menos cansativas, com menos recreações...; deveriam ser cobrados os conteúdos em formas de avaliações escritas periódicas; muitas vezes as aulas são para fazer brincadeiras... mostram que a mudança, nesse caso, começou a acontecer na sala de aula, porém ainda de forma unilateral, ou seja, não foi bem assimilada por todos os alunos.

Tais colocações fazem pensar na dificuldade do ser humano contatar com suas intimidades, seus sentimentos e desejos, razão pela qual, ao lidar com questões mais concretas e delimitadas, pode parecer que está aprendendo com maior objetividade ${ }^{(18-20)}$.

Mesmo diante de tais apontamentos, nossa trajetória, no exercício da docência, dá a convicção de que estamos seguindo rumo a caminhos que, certamente, favorecerão o desenvolvimento de pessoas.

\section{REFERÊNCIAS BIBLIOGRÁFICAS}

1. Brant MJCGC, Antunes MJM. Concepções pedagógicas: influência na educação e na prática de enfermagem. Sínteses do $47^{\circ}$ Congresso Brasileiro de Enfermagem; 1995; Goiânia, Goiás. Goiânia: Centro Editorial e Gráfico UFG; 1995.

2. Munari DB, Rodrigues ARF. Enfermagem e grupos. Goiânia (GO): AB Editora; 1997.

3. Stacciarini JMR, Esperidião E. Repensando estratégias de ensino no processo de aprendizagem. Rev Latino-am Enfermagem 1999 dez; 7(5):59-66.

4. Machado JLM, Caldas A, Bertoncello NMF. Uma nova iniciativa na formação dos profissionais de saúde. Interface: comunicação, saúde, educação 1997 ago; 1(1):147-56.

5. Santomé JT. Globalização e interdisciplinaridade: o currículo integrado. Porto Alegre (RS): Artes Médicas; 1998.

6. Leoni MG. Autoconhecimento do enfermeiro na relação terapêutica. Rio de Janeiro (RJ): Cultura Médica; 1996.

7. Weil P. Organizações e tecnologias para o terceiro milênio: a nova cultura organizacional holística. Rio de Janeiro (RJ): Rosa dos Tempos; 1993.

8. Burnier R. Em direção a uma ordem mundial. In: Brandão DMS, Crema R. O novo paradigma holístico: ciência, filosofia, arte e mística. São Paulo (SP): Summus; 1991.

9. Ribeiro JP. Educação holística. In: Brandão DMS, Crema R. Visão holística em psicologia e educação. São Paulo (SP): Summus; 1991.

\section{CONSIDERAÇÕES FINAIS}

O presente estudo salienta a importância do autoconhecimento para a formação do profissional enfermeiro, mostrando que a estrutura de uma disciplina (Saúde Mental I) pode viabilizar esse processo. Para isso, algumas estratégias de ensino e determinados conteúdos ministrados podem funcionar como elementos facilitadores.

Os resultados apontam que o processo psicopedagógico implementado auxilia na formação, indo além de ensinamentos científicos, descobrindo e valorizando a pessoa que existe dentro de cada profissional. Com isso, enquanto docentes, pretendemos seguir nessa mesma trajetória, embora reconheçamos que essa tarefa exige esforço e dedicação, o que extrapola o esquema didático tradicional, que, certamente, persiste no cotidiano do ensino de muitos cursos de graduação em enfermagem.

É inegável a necessidade do envolvimento do docente como pessoa nesse processo, uma vez que, a todo o momento, estamos revendo nossas posturas, nossos sentimentos e valores. Talvez seja esse o maior desafio para as instituições responsáveis pela formação do enfermeiro.

10. Greiner PA, Valiga TM. Creative educacional strategies for health promotion. Holist Nurs Pratic 1998; 12(2):73-83.

11. Naranjo C. Educando a pessoa como um todo para um mundo como um todo. In: Brandão DMS, Crema R. Visão holística em psicologia e educação. São Paulo (SP): Summus; 1991.

12. Taylor CM. Manual de Enfermagem Psiquiátrica de Mereness. Porto Alegre (RS): Artes Médicas; 1992.

13. Goleman D. Inteligência emocional. Rio de Janeiro (RJ): Objetiva; 1996.

14. Moscovici F. Razão e emoção. Salvador (BA): Casa da Qualidade; 1997.

15. Moretto RA, Mansur OFC, Araújo J Jr. Humanismo e tecnicismo na formação médica. Rev Bras Educ Med 1998 jan/abr; 22(4):19-25.

16. Saeki T, Munari DB, Alencastre MB, Souza MCB. Reflexão sobre o ensino de dinâmica de grupo para alunos de graduação em enfermagem. Rev Esc Enfermagem USP 1999 dez; 33(4):342-7.

17. Segre M, Ferraz FC. O conceito de saúde. Rev Saúde Pública 1997; 31(5):538-42.

18. Filizola CLA, Ferreira NMLA. O envolvimento emocional da equipe de enfermagem: realidade ou mito? Rev Latino-am Enfermagem 1997 mai; 5(n.especial):9-18.

19. Rodrigues ARF, Scatena MCM, Giaconi AV, Santana JA. Opinião de enfermeiros a respeito de suas interações com os pacientes. Anais do $1^{\circ}$ Congresso de Saúde Mental do Estado do Rio de Janeiro; 1997; Rio de Janeiro: TeCorá: Instituto Franco Basaglia; 1997. 
20. Santos ML. O trabalho dos "Anjos de Branco": um estudo em um hospital geral público. Anais do $1^{\circ}$ Congresso de Saúde Mental do Estado do Rio de Janeiro; 1997; Rio de Janeiro: TeCorá: Instituto Franco Basaglia; 1997.

21. Munari DB. Processo grupal em enfermagem: possibilidades e limites. [tese]. Ribeirão Preto (SP): Escola de Enfermagem de Ribeirão Preto/USP; 1995.

22. Jorge MSB. Situações vivenciadas pelos alunos de enfermagem durante o curso no contexto universitário, apontadas como norteadoras de crises. Rev Esc Enfermagem USP 1996 abr; 30(1):138-48.

23. Jorge MSB. Indo em busca de seu plano de vida: a trajetória do estudante universitário. Florianópolis (SC): Papa-Livro; 1997.

24. Coronel LCl. Grupo de reflexão. In: Zimerman DE, Osório LC, organizadores. Como trabalhamos com grupos. Porto Alegre (RS): Artes Médicas; 1997.

25. Zimerman DE. Grupos de educação médica. In: Zimerman DE, Osório LC, organizadores. Como trabalhamos com grupos. Porto Alegre (RS): Artes Médicas; 1997.

26. Bardin L. Análise de conteúdo. Lisboa (Portugal): Edições 70; 1977.

27. Delgado PGG, Lacerda L, Santos ML. Subjetividade, sofrimento psíquico e trabalho em saúde: uma proposta de disciplina eletiva para a graduação em medicina. Anais do $1^{\circ}$ Congresso de Saúde Mental do Estado do Rio de Janeiro; 1997; Rio de Janeiro: TeCorá: Instituto Franco Basaglia; 1997.

28. Haddad MCL. Enfermagem médico-cirúrgica: uma nova abordagem de ensino e sua avaliação pelo aluno. Rev Latinoam Enfermagem 1993 jul; 1(2):97-112.

29. Chaves EC. O desempenho de papéis sociais numa relação de ensino-aprendizagem. Rev Latino-am Enfermagem 1993

dez; 1 (n.especial):35-42. 